\title{
Levels of Induction and Deduction among Pre- Service Classroom Teachers and its Relation to their Learning Styles
}

\author{
Nahil M. Aljaberi and Eman Gheith \\ University of Petra \\ Amman, Jordan
}

\begin{abstract}
This work can be considered as a descriptive study to determine the level of pre-service classroom teachers' ability to describe inference (induction and deduction) in Mathematics and Science subjects in the educational department. It also aims to define their learning styles to find the relationship between their inference abilities and learning styles. A sample of 144 pre-service classroom teachers was selected for this study. Data were collected using the Kolb 's learning style inventory to determine the teachers' learning styles. A second test, which includes 25 items, was used to measure induction and deduction abilities in Mathematics and Science. The study demonstrated a low inference ability in both Mathematics and Science. A lower score was achieved in Mathematics. The prevalent learning style was accommodator. There was no relation between inference abilities among pre-service teachers and their learning styles. These results will help curriculum designers to prepare classroom training programs and design materials in Mathematics and Science that are suitable for teaching and learning.
\end{abstract}

Keywords: induction; deduction; inference; learning style; pre-service classroom teachers.

\section{Introduction}

Inference has an active link to intelligence and learning. Allam (2010) asserts that the most important factor of intelligence is the ability to infer, which means the ability to extract the rules or principles. Therefore, inference forms the cornerstone to learning and development and progress of societies. Mullis, Martin and Foy (2005) assert that human thinking is based on a unique talent of generalizing knowledge from several examples and observations. This mental activity called inference (induction and deduction) is considered a fundamental component of general thinking and is related to other types of thinking. The inductive approach is appropriate for teaching Mathematics, especially at the primary stages because of extrapolation's association with concrete examples of 
life, and the ability of this approach to detect generalizations and reach numerical patterns. Math and Science subjects are related and intertwined, which mean that science subjects depend on induction to build knowledge. At the same time, deduction is one of the most important way to think about Mathematics and mathematical proofs (Wasserman and Rossi 2015). On the other side, this does not mean that deductive reasoning is separate from inductive reasoning, but there is a complementary relationship between them. Gagani and Misa (2017) confirmed that induction and deduction are an essential mathematical process that extend to life problems.

The relationship between the induction and the deduction processes explained is that induction is an upward process build from concrete experiences to the formation of generalities and reaches facts that range in abstraction to the level of theories that represent the most abstract. Deduction is a downward process from the more general to more specific. In general, inductive reasoning is the path of innovation and invention (Qatami, 2009). The ability to infer is positively related to problem-solving since inference is an organized mental investigation process aimed at reaching an unknown fact with the help of known facts and information (Qatami, 2009). Abu Zeina (2010) agrees that inference (induction and deduction) is an essential aspect of mathematical thinking. Also, one of the essential methods of proof in mathematics. Induction and deduction are also two of the critical methods of proof in mathematics (Basaran et al., 2015).

Kolb (2005) considers the learning process as the process by which knowledge is created and produced through the transfer of experience. So, learning about an individual's learning style is helping to discover an individual's learning styles and provide him with an opportunity to find tools that he or she can use in the learning process (Hawk \& Shah, 2007). Teaching is a reflective process in which the teacher is reflecting on his/her teaching practices to be sure that it is suitable for the students' learning styles (Sims \& Sims, 1995). Manolis et al. (2013) assert that learning became heavily dependent on self-learning, so it was necessary to shift from indoctrination to flexible, individualized teaching methods that is suitable for students and make learning and teaching more fun and attractive for both teachers and students.

Knowing and defining a student's learning style is considered as a learning tool to increase individuals' understanding of the learning process. Hawk and Shah (2007) assert that the emergence of many learning styles over the past 25 years has increased attention to the idea that students learn in a variety of ways because the same teaching method does not work for every student. Identifying an individual's learning style is a starting point for exploring how a student learns better and distinguishing characteristics and methods of individual learning. It helps the teacher to recognize individual differences between students and their learning styles. It also helps them to choose different teaching methods, introduce the lessons to all students in their different own styles and helps to increase student motivation for learning and helps boost creativity and break routines (Wyrick, 2003; Kolb, 2005). 
Gokalp (2013) emphasizes that identifying learning styles and analyzing the factors that affect them is mainly reflected not only in the learning process but also in academic achievement and performance. As students differ in their learning styles, this leads to different ways they can learn and process knowledge, many researchers have defined the learning style as the particular way the learner handles. Process information, learning methods are not only concerned with what the learner learns but with how the learner prefers to learn. Thus, determining the relationship between learning styles, inductive and deductive reasoning, can provide teachers with valuable information that helps evaluate their curricula and design their teaching logically based on the relationship between mathematical thinking and learning styles (Arslan, Göcmencelebi \& Tapan, 2009).

Kolb (2005) also emphasizes that the learning style depends on the type of personality, scientific specialization, career choice, education roles, and functions of an individual's employment. Barrish (1970) assumes that convergent thinking corresponds with the induction strategy more than an interference deduction thinking strategy that corresponds with divergent thinking. The inference is a way of thinking and a way of teaching, especially in Mathematics and Science. Besides, many researchers point out that the congruence between teaching strategies and learning styles enhances achievement in students and supports the positive attitudes towards the learning process (Rogers, 2009; Tulburn, 2011). Kolb believes that students of the same major mostly have the same learning styles, and this is consistent with the characteristics of the college or specialization they are studying. In his theory, Kolb (2005) asserts that students of science specialization become more analytical, but less creative while students of literature become more creative and less analytical (Montgomery \& Groat, 1998).

This study aims at explaining the learning styles, determining the abilities of preservice teachers in inference (induction and deduction) in Mathematics and Science, investigating the relationship between learning styles and inference abilities (induction and deduction). These issues influence the process of preparing pre-service teachers to teach Mathematics and Science. Moreover, this study aims to help teachers to choose suitable methods of teaching these two subjects and to overcome the difficulties students face in learning these subjects. This study will also set milestones for those who set programs for preparing teachers to develop and improve curricula. This research also points to the importance of examining the inference level among the learners and the needed information about student performance and their suitable learning styles. In doing so, teachers will have insight into designing instruction that is appropriate for students.

\section{Literature review}

Many studies have emphasized the importance of considering the learning styles of the students as a response to the new orientations that focus on the learner, his learning style and needs. The following is a review of many studies. In a comparative study done by Atta, Ayaz and Nawaz (2015) on the impact of 
two teaching methods (induction and induction) on achievement and performance, students of the elementary level were selected for a pre-test and post-test and the results concluded that there was a difference in achievement and performance between the two groups in favor of the group studied by the induction method. In the case study of Gökkurt, Soylu and Sabin (2014) which aimed to analyze Mathematics proof skills that include induction and deduction in teaching Science, the results showed that the majority of the student were able to use induction in the math proof successfully.

Lawson's (2005) study aimed to define the role of inference (induction and deduction) in scientific inquiry through a controlled experiment designed to determine the role of induction and deduction in the process of reasoning and its relationship with the neuro-modeling field. The result of the study indicated that induction does not play a role in achieving thinking tasks and that students were providing attention to deductive thinking operations. Barrish (1970) defined the relation between convergent thinking level and inference teaching strategies, relying on the assumption that the students of the high level of convergent thinking perform higher by using inductive teaching strategies than using deductive teaching strategies. The results showed that learning simple Mathematics content suits deduction more than induction strategies.

In the Mathematics and Science learning processes, it is important to consider the student learning style in order to identify differences among learners to design effective instruction that are appropriate for all learners. An example of a study dealing with the learning styles and its role in learning and its relation to some varieties was done by Talafha and Zoghoul (2009). The study was about the favorable learning styles of the students of Muta University and its relation to gender. The study showed that the different parts of the brain are responsible for learning different things.

Sudria et al. (2018) studied the effects of Kolb's learning styles on the learning of chemistry and the achievements of eleventh-grade students. Students using inductive guided inquiry learning, and distinguished students with academic excellence based on the national test. The study indicated that the convergent style is prevalent, followed by the assimilator style, the divergent style, and finally, the accommodator. The study confirmed the high impact of the methods of learning based on the inductive inquiry on the achievement and learning performances. The superiority of the convergent style compared with the accommodator in learning chemistry depends on concrete evidence and laboratory work.

Abu Hashim and Kamal (2007) aimed to recognize the nature of thinking and learning styles of students of a medical university according to their different academic levels. The study used Kolb (2005) learning styles inventory and the list of Sternberg (1994) thinking methods. The study showed a significant statistical positive correlation between the following learning styles (accommodation, convergent, divergent, assimilation) and several thinking styles (legislative, executive, judgmental). The results indicated that convergent 
and divergent methods of learning are prevalent for students of literary disciplines.

Tulbure (2011) described the aspects of teaching strategies that lead to better academic performance for the student according to the learning styles of the student himself. Kolb's (2005) inventory was again used to define the learning styles, in addition to an achievement test. The results indicated that the students who have different styles achieve better results when choosing teaching strategies that respond to their preferred learning styles. Arslan, Göcmencelebi and Tapan (2009) defined the relationship between pre-service teacher thinking (induction, deduction inference, and undefined) and learning styles. The study showed that students prefer induction more than deduction. Also, they found that there was a significant relationship between thinking in both Mathematics and Science. Students prefer induction more than deduction because it depends on collecting notes and experience, which reflected in their everyday problems.

The study of Khasawneh, Abu-Tineh and Obeidat (2006) explored the relationship between the learning style and the GPA (Grade Point Average) for the students of Hashemite University. As the prevalent learning style is the assimilator, the users of this style generally score higher in their academic tasks over their peers who use other learning styles. There were no statistical differences with reference to gender, academic level or major.

\section{Aims and significance of the study}

One of the greatest difficulty for pre-service classroom teachers is the poor performances of students in Mathematics and Science, and this is even more pronounce in Mathematics. The relationship between the teachers' learning styles and their inference ability helped them to find strategies to teach Mathematics and Science. There are few studies of the relationship between the ability to perform inference (induction and deduction) and the learning styles for pre-service teachers. This study will enable future curriculum design staff as well as teachers to develop curriculum to include induction and deduction skills and organize them according to the learning styles of their students.

\section{Study questions}

This study focuses on investigating the learning styles used by the pre-service classroom teachers at the University of Petra. It also examines their ability to inference (induction and deduction) in both math and science subjects. The study aimed to answer the following questions:

- What is the level of ability for the pre-service classroom teachers to inference (induction and deduction) in Mathematics and Science?

- Is the level of ability of the pre-service classroom teachers to inference (induction and deduction) in Mathematics subject different from that of science subject?

- Are there differences in the level of ability of the pre-service classroom teachers to inference (induction and deduction) in Mathematics and Science subjects based on major at high school and academic-year level?

- What are the learning styles that are common in the pre-service classroom teachers? 
- Are there differences in the pre-service teachers' ability level of inference (induction and deduction in Mathematics and Science subjects according to their learning styles?

\section{Method}

\section{Study population and sample}

The sample consisted of 144 teachers enrolled in the Mathematics and Science courses in the second semester of the academic year 2018/2019. Among them, there were sixteen (16) teachers from the first-year, twenty-nine (29) from the second-year, fifty-four (54) from the third year and forty-five (45) teachers from the fourth year. The high school streams were as follows: twelve (12) teachers from the Science stream, seventy-one (71) teachers from the Literature stream, another seventy-one (71) from the IT stream, and seventeen (17) teachers from the other streams. All participating teachers were females.

\section{Operational definitions}

Inference can be defined as the use of the mind to derive conclusions from specific data and in a general form, and this includes both induction and deduction (Merriam-Webster, 2019). Induction is a thinking operation for the transition from private to general (from individual to holistic or generalizations) to reach an extensive conclusion through single facts. Induction is the discovery of a situation similar to cases with a fixed and frequent relationship (AlMashharawi, 1999). It is reaching a base or entire judgment from processing all individual cases. Incomplete induction happens when processing some cases or partial provisions reaches to a general rule (Obaid and Afaneh, 2003). Using induction, we can generalization through some examples or individual cases, which includes general interpolation, meaning expressing the general rule through using linguistic sentences, and also discovering a pattern or reaching a general rule (Abu Zeina, 2007). Deduction is the process of deduction; reaching facts through general principles (from holistic to partials) happens through connecting between previous remarks and information and then judging it. Each part of the thinking process can have a conclusion, and every work you do or think of must follow a specific outcome (Hussein and Fakhro, 2015). Learning style is the learning style that is preferred by the learner and used for his/her study and the one that he/she also uses for processing, coding, and revising information. In this study, it is defined procedurally as the group of indicators and cognitive skills that are relatively stable in the interaction of the individual with the surrounding environment for understanding and adapting to it.

\section{Learning styles for Kolb (2005)}

Kolb (2005) presented an experimental learning theory that emphasized experience as a source of learning. Kolb (2005) developed a model in 1984 based on several themes. The importance and role of activity during learning and learning is the result of interaction between the student and its environment, and learning is creating knowledge according to the constructivist theory and is a comprehensive process of adaptation to the world and not limited to the results of cognitive and thinking. Kolb's (2005) theory for learning depends on 
two axes: the horizontal axis represents "action" and the vertical axis represents "knowledge". The ending of the horizontal axis refers to the mission. In contrast, the ending of the left relates to action and the ending of the right to observation. At the same time, the ending of the horizontal axis points to a theoretical (abstract) dimension where the upper end relates to the sense and feeling, while the lower end refers to thinking. At the cross area of the two axes of Kolb (2005), four divisions are formed that represent the learning styles. Figure 1 shows these styles. The two axes cross to form four divisions that present the following learning styles: divergent - concrete experience + reflective observation, assimilator - reflective observation + abstract conceptualization, convergent abstract conceptualization + active experimentation, accommodator - active experimentation + concrete experience.

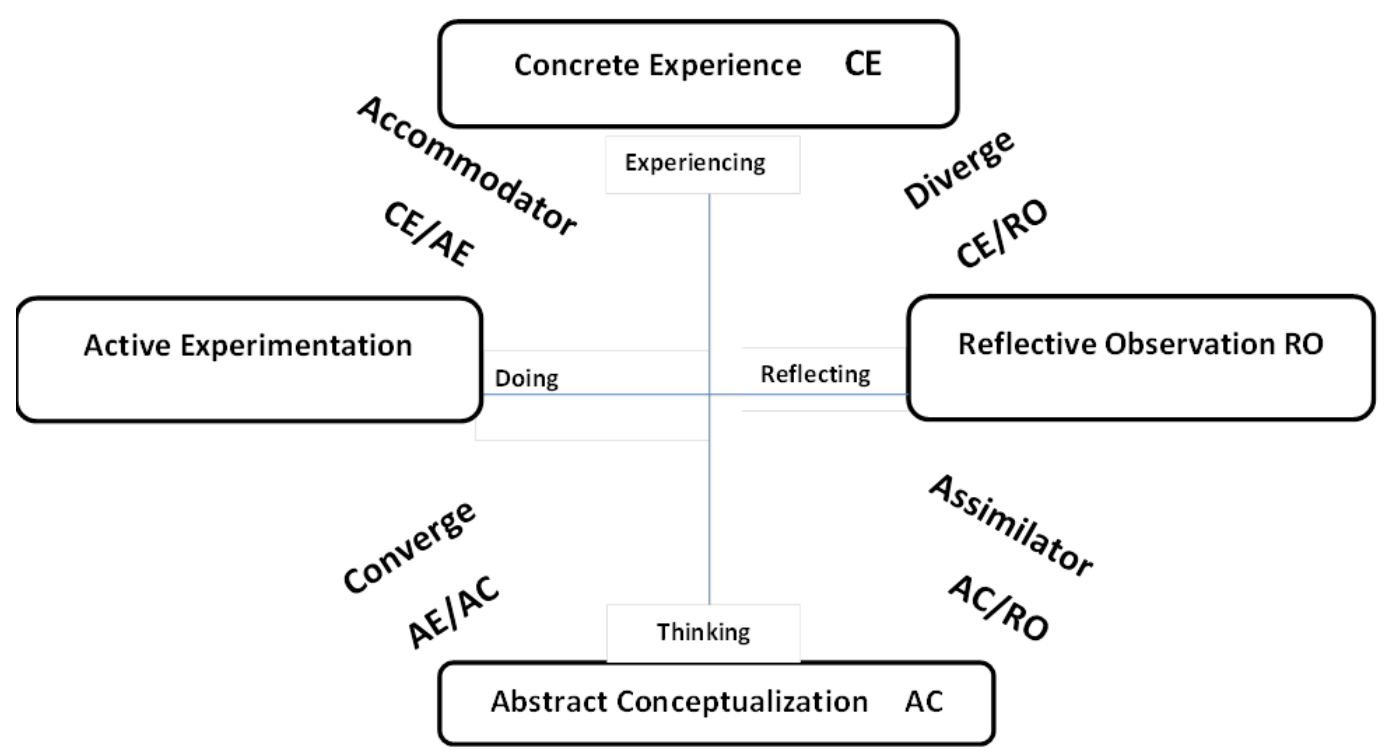

Figure 1: Kolb's (2005) Experiential Learning Model

The Concrete Experience (CE) style

The learners' sense to the piece of information is highly based on the sensory experience, or the reality perceived by his feelings and senses. People experience real learning through observation and live examples. Therefore, they find the theoretical way to be useless in learning as they perform better with examples and witnesses, especially the ones they have experienced previously.

Reflective Observation (RO) style

The learners' sense of information is based on attending and observation. Therefore, they highly depend on careful observation before judging. They prefer learning situations that allow them to monitor and they prefer introvert objectively, and their interaction is less in the group's. This type of learner wants the trainer to reflect on his/her own experiences rather than on general ones.

Abstract Conceptualization style (AC)

The learners' sense of information based on an imaginary analytic view that depends highly on logical thinking and mental evaluation. Mostly, they prefer 
objects and codes more than being with people. They feel bored if the learning circumstances are messy and dependent on discovery. Case studies, theoretical readings and mental exercises are considered appropriate for this type of learners. Other methods might not appeal to them.

Active Experimentation (AE) style

The learners' sense of learning depends on direct experience through practice. They learn through homework or groups of discussion and learn better when they connect to an activity or homework or a group discussion. They hate passive learning like lectures. They intend to be open to others, to solve problems, to form small discussion groups, and to receive feedback from peers. People of this type believe in seeing and touching everything personally to define his/her standards.

Convergent style

People of this style can solve problems and situations that require a straightforward answer. They call themselves convergent because they can find correct answers that are natural to the problem. Their common ability is forming fixed abstract concepts and working. These usually are emotional and prefer working with the materials. Their concerns are generally closed and intend to study majors in natural sciences and engineering.

Divergent style

People with this style uses sensory and reflective observation. They called themselves divergent because they usually have their own ideas and can invent their own working solutions. Their wide mental concerns and their power is in their imaginary abilities. They like to view cases from multiple angles, perform better in educational situations that require producing ideas, mainly brainstorming. They participate effectively with others and they intend to study humanities and arts.

Assimilator style

People of this style use abstract concepts and reflective observation. They called themselves assimilators because they like to assimilate divided elements everywhere. Their power is found in creating theoretical models in addition to inference reasoning. They use abstract concepts and do not intend to apply thoughts practically. They aim to study Science and Mathematics and they usually like to do work that requires planning and investigation.

Accommodator style

People of this style use sensory experiences. They are the opposite of assimilators. They are named as accommodators because they have the skills and intelligence in adapting to the new circumstances. They can perform plans and experiences, integrate with new experiences, and solve problems (using trial and error) using other people's experiences. They are impatient when they face a theory that is opposite to their opinions and they usually ignore it. They tend to study art, practical topics, trade, marketing, and coordination (Kolb, 2005; Hawk \& Shah, 2007). 


\section{Study tools}

To collect data, the researchers have used two instruments: the first one is an inference (induction \& deduction) test and the second one is Kolb's (2005) scale of learning styles inventory. Table 1 shows the information about these instruments.

Table 1: The instruments used and their reliability coefficient values

\begin{tabular}{|l|l|l|c|}
\hline Measures & No. of items & Measurement topic & $\begin{array}{l}\text { Reliability } \\
\text { Cronbach-Alpha }\end{array}$ \\
\hline $\begin{array}{l}\text { Inference (induction } \\
\text { and deduction) test }\end{array}$ & $\begin{array}{l}\text { 13 Science items } \\
\text { 12 Mathematics items }\end{array}$ & $\begin{array}{l}\text { To measure inference } \\
\text { in Science and } \\
\text { Mathematics }\end{array}$ & $\alpha=0.71$ \\
\hline $\begin{array}{l}\text { Kolb's scale of } \\
\text { learning styles } \\
\text { inventory }\end{array}$ & 9 items & $\begin{array}{l}\text { Measure learning } \\
\text { style }\end{array}$ & $\alpha=0.92$ \\
\hline
\end{tabular}

\section{Study limitations}

The limitations on generalizing the findings of this study are as follows: this study is limited to pre-service teachers at the University of Petra (a private university in Amman, Jordan), the results are limited to the reliability and validity of the scale specifically designed for this study and all participating teachers were females, only for not finding male students in the pre-service classroom teacher major.

\section{Results of the study}

\section{The level of inference (induction and deduction)}

We have calculated the frequencies and percentages to the answers of students on the inference scale paragraphs. Depending on the following categorization to define the ability level to inference, the degree between 86-100 is excellent, 70-85 is very good, $50-69$ is acceptable and less than 50 is weak. Table 2 presents these results.

Table 2: Frequencies and percentages of the students' numbers on the inference (induction and deduction) scale on the overall test and in Mathematics and Science

\begin{tabular}{lcccccc}
\hline & \multicolumn{2}{c}{ Overall test } & \multicolumn{2}{c}{ Mathematics } & \multicolumn{2}{c}{ Science } \\
\hline Level & Frequencies & Percentage & Frequencies & Percentage & Frequencies & Percentage \\
& & & & & & \\
\hline Excellent & 1 & $0.7 \%$ & 5 & $3.5 \%$ & - & - \\
\hline Very Good & 17 & $11.8 \%$ & 16 & $11.1 \%$ & 28 & $19.4 \%$ \\
\hline Acceptable & 63 & $43.8 \%$ & 47 & $32.6 \%$ & 65 & $45.1 \%$ \\
\hline Weak & 63 & $43.8 \%$ & 76 & $52.8 \%$ & 51 & $35.4 \%$ \\
\hline
\end{tabular}

From Table 2, we can see that the majority of students either have an acceptable ability level or are very weak. Both levels have the same percentage of $43.8 \%$. Only 17 students, representing $11.8 \%$ of the sample, have scored very good and only 1 student managed to score above 85 points. The same trend is apparent in the individual subjects. In Mathematics, the higher percentage $52.8 \%$ was for the weak level teachers, followed by $32.6 \%$ for acceptable and $11.1 \%$ for good and $3.5 \%$ for excellent, and this clearly shows a huge deficiency in the students' ability to inference. In Science, the higher percentage of $45.1 \%$ was obtained in 
the acceptable, level, followed by $35.4 \%$ for weak and $19.4 \%$ for very good. Surprisingly, no student was able to perform at the excellency level in Science.

The means, standard deviations and the value of $t$ for the pre-service teachers' answers on the inference scale was calculated and the results are presented in Table 3.

Table 3: The mean, standard deviation and $t$ value for pre-service teachers' scores in inference in Mathematics and Science

\begin{tabular}{llll}
\hline Subject & Mean & Standard deviation & Indication \\
\cline { 1 - 2 } Mathematics & 46.8 & 20.9 & \multirow{t}{t}{$=4.46$} \\
\cline { 1 - 2 } Science & 56.7 & 16.4 & \\
\cline { 1 - 3 } Total & 51.7 & 19.4 & \\
\hline
\end{tabular}

From Table 3, we can see that the mean for pre-service teachers' degrees on the inference scale is 51.7, and the standard deviation is 19.4. The mean in Mathematics is 46.8 and standard deviation is 20.9 while for Science, the teachers' mean is 56.7 , and the standard deviation is 16.4 . However, there was a significant statistical difference in students' mean in Mathematics and Science in favor of Science.

The mean and standard deviation of the teachers' degree on the scale of the ability to inference, according to the stream at high school and the academic year was calculated. Table 4 presents these results.

Table 4: Mean and standard deviations of student's degrees on inference scale according to stream and academic year

\begin{tabular}{|c|c|c|c|c|c|c|c|c|}
\hline \multirow{2}{*}{ Variation } & & \multirow{2}{*}{ Number } & \multicolumn{2}{|c|}{ Mathematics } & \multicolumn{2}{|c|}{ Science } & \multicolumn{2}{|c|}{ Total } \\
\hline & & & $\mathrm{M}$ & S.D & $\mathrm{M}$ & S.D & $\mathrm{M}$ & S.D \\
\hline \multirow[t]{6}{*}{ Stream } & Scientific & 12 & 49.4 & 21.1 & 60.9 & 21.9 & 55 & 18.3 \\
\hline & Literature & 48 & 42.2 & 20.1 & 57.4 & 18.2 & 48.9 & 15.7 \\
\hline & IT & 71 & 49.4 & 21.3 & 55.4 & 17 & 52.4 & 14.9 \\
\hline & Others & 13 & 47.5 & 20.9 & 57.9 & 16.4 & 52.5 & 15.1 \\
\hline & $\mathrm{F}$ & & 1.004 & & 0.42 & & 0.73 & \\
\hline & Sig & & 0.39 & & 0.74 & & 0.54 & \\
\hline \multirow{6}{*}{$\begin{array}{l}\text { Academic } \\
\text { year }\end{array}$} & First & 16 & 47.3 & 23.2 & 65. & 16.3 & 46.1 & 14.7 \\
\hline & Second & 29 & 53.5 & 19.4 & 57.1 & 17 & 55.2 & 16 \\
\hline & Third & 54 & 49.1 & 21.9 & 53.3 & 14.9 & 51.2 & 15.2 \\
\hline & Fourth & 45 & 39.7 & 18.2 & 57.6 & 16.4 & 47.8 & 15.1 \\
\hline & $\mathrm{F}$ & & 3.39 & & 2.27 & & 1096 & \\
\hline & Sig & & 0.02 & & 0.08 & & 0.123 & \\
\hline
\end{tabular}

Referring to Table 4 above, we notice that there are no significant statistical differences between the calculated means except the differences between the student's degrees on the inference scale in Mathematics for the second academic year. The mean in the inference scale in Mathematics is 53.5, while the mean for students on the same scale of the fourth year is 39.7. This difference is statistically significant. 


\section{Learning style}

Students were categorized in the four learning styles according to their response to the learning styles scale. Table 5 presents the number of students and their mean according to the Kolb's scale

Table 5: Number of pre-service teachers and their percentage categorized within the four styles as per the Kolb's scale

\begin{tabular}{lll}
\hline Style & Frequency & Percentage \\
\hline Divergent & 34 & $23.6 \%$ \\
\hline Accommodator & 69 & $47.9 \%$ \\
\hline Convergent & 13 & $9.0 \%$ \\
\hline Assimilator & 28 & $19.4 \%$ \\
\hline
\end{tabular}

From Table 5, we can see that pre-service teachers with accommodator style is $47.9 \%$, which is the highest average followed by the divergent learning style with $23.6 \%$, the assimilator style with $19.4 \%$ and the convergent had the lowest percentage of only $9.0 \%$.

The researchers calculated the mean of the students' degrees and their standard deviation on the inference scale both in Mathematics and Science according to the four styles of learning. Table 6 presents these results.

Table 6: Means and standard deviation for preserve teacher's grades on inference scale according to the four learning styles

\begin{tabular}{lllllll}
\hline \multirow{2}{*}{ Learning styles } & \multicolumn{2}{l}{ Scale (entire) } & \multicolumn{2}{l}{ Science } & \multicolumn{2}{l}{ Mathematics } \\
\cline { 2 - 7 } & S.D & M & S.D & M & S.D & M \\
\hline Divergent & 16.2 & 50.7 & 19.9 & 57.5 & 20.4 & 45.4 \\
\hline Accommodator & 16.7 & 50.2 & 16.5 & 55.9 & 20.7 & 45.5 \\
\hline Convergent & 6.9 & 51 & 14 & 57.5 & 17.6 & 45 \\
\hline Assimilator & 13.9 & 55.6 & 12.6 & 57.3 & 21.1 & 54.1 \\
\hline F & 0.83 & & 0.1 & & 1.37 & \\
\hline Sig & 0.48 & & 0.96 & & 0.25 & \\
\hline
\end{tabular}

Looking at Table 6, we notice the value of F calculated to test the differences between the students' averages on the entire scale, or Mathematics and Science, according to the four learning styles with no statistically significant differences.

\section{Discussion}

The results show that the level of the ability to inference generally was weak for pre-service teachers as $43.8 \%$ of the respondents had a weak inference ability. And another $43.8 \%$ teachers could only score in the acceptable range. Very found teachers could score in the very good or excellent categories. The results were very similar for both Mathematics and Science. These results point at an apparent weakness in their ability of inference and this maybe because the students were from the literature stream. This is consistent with the results of the university competence exam held by the Ministry of Higher Education for all students who graduated from Jordan universities, which show weaknesses in Mathematics and Science for pre-service classroom teachers. This alerts the necessity of looking into the Math curriculum and methods of teaching at all 
levels and using induction and deduction as teaching strategies and thinking skills in Math and Science curricula.

The study also showed apparent statistical differences in the level of the ability to inference (induction and deduction) in Math and Science. The accommodator style was found to be the dominant learning style. This style concentrates on the sensory experiences and ongoing work, and these are the requirement for induction and deduction processes in Science. Students of pre-service teacher majors are in the preparation phase to become teachers at the primary level. Thus, their curriculum concentrates on practical situations and solving real issues and transforming educational science theories and interpreting them to educational life situations. This corresponds with Kolb (2005) approach, which emphasized that people of this style suit individuals of professions like sales and social services and education. The outcomes from this study is slightly different from the findings of Tulbure (2011), which showed that the prominent learning style is assimilator for pre-service teachers. This style concentrates on the abstract concepts and working experiences together. This style is appropriate for deduction that Math depends on, especially the proof subject. This is a clear difference in the ability in induction and deduction for the students of Math and Science.

Furthermore, this study showed that the students of the divergent style reached a percentage of $23.6 \%$, which is close to that found in Tulbure (2011). Individuals of this style have a good level of induction thinking. The assimilator style of learning reached a percentage of $19.4 \%$ in this study, and it is much less than the study of Tulbure (2011), where the percentage was $31 \%$. The individuals of this learning style have a background in Math and Science and Physics according to Kolb (2005), which explains the weakness of the study group in inference (induction and deduction). The difference between the two studies might refer to the individual differences between the two different study groups and the nature of the educational program applied in a different environment. No statistically significant differences were found with regards to students from different academic year or majors.

Nevertheless, there were slight difference between students' averages on the inference scale in Math between students of the second and fourth year, in favor of the second-year students. This can be explained by the fact that the students of the second year were studying Math and Science subjects, while in the fourth year, they focus on field training. These results are similar to the study done by Khasawneh, Abu-Tineh and Obeidat (2006), where the survey concluded that there were no statistically significant differences based on academic level or major.

\section{Conclusion}

This study aims to define the level of inference (induction and deduction) for pre-service classroom teachers and to determine their preferred learning styles. The objective was also to find the relation between those styles and their level of inference. The study concluded that the level of students in inference (induction 
and deduction) was weak. The students differ in their level of inference (induction and deduction) in Mathematics and Science, in favor of Science. Furthermore, the students of the second year performed better on the inference scale than the students of the fourth year, and that was due to the fact that they studies Mathematics and Science in their second year. No differences were found between the students from the high school stream in the level of their ability to inference. The dominant learning style was found to be accommodator while the least popular style was found was to be convergent. This study also showed that there were no statistically significant differences between the survey groups in their inferencing levels based on academic level or major.

\section{Recommendations}

In light of the results obtained, the following recommendations are made:

- This study recommends the necessity of evaluating programs and educational curricula for improving the methods and strategies of the students' learning in a way that corresponds to their different learning styles and which are familiar to them and also suitable for their majors and future professions.

- Educational curricula must focus on the skills of induction and deduction in the different educational stages and in all subjects but especially Mathematics and Science.

- Concentrate on inference (induction and deduction) as methods of teaching, in addition to the thinking styles in pre-service classroom teachers' preparation program.

- Use different methods for teaching and training the students on different types of learning that suit their different styles.

\section{References}

Abu Hashim, A., \& Kamal, S. (2007), Methods of Learning and Thinking in Gaza, (Unpublished PhD. Dissertation), Ain Shams University, Joint Graduate Program with the Faculty of Education in Gaza, Palestine.

Abu Zeina, F. (2007). Numbers and its' application in Mathematics and Life (2nd ed). Amman, Jordan: Dar Al-Masirah.

Abu Zeina, F. (2010). Development of school mathematics curricula and methods of teaching mathematics. Amman, Jordan: Dar Wael Publishing.

Al Aila, H. (2012). The Effect of a Suggested Learning-Based Program to Develop Mathematical Thinking Skills among Fourth Grade Students in Gaza Governorates (Unpublished Master Thesis), Al-Azhar University, Gaza.

Al Musaideen, M. (2011). The Effect of the aspect Learning styles among Mu'tah University Students on the Model of Kolb in both their Emotional Intelligence and their Motivation for Achievement (Unpublished Master Thesis), Mu'tah University.

Allam, S. (2010). Educational and Psychological Measurement and Evaluation, Cairo, Egypt: Dar Alfeker al-Arabi.

Al-Mashharawi, I. (1999). A Proposed Program for the Development of Mathematical Thinking among Eighth Grade Students in Gaza (Doctoral dissertation, Ein-Shams University, Faculty of Education).

Arslan, C., Göcmencelebi, S. I., \& Tapan, M. S. (2009). Learning and reasoning styles of pre-service teachers': inductive or deductive reasoning on science and 
mathematics related to their learning style. Procedia - Social and Behavioral Sciences, 1(1), 2460-2465. https://doi.org/10.1016/j.sbspro.2009.01.432

Atta, M. A., Ayaz, M., \& Nawaz, Q. (2015). Comparative Study of Inductive \& Deductive Methods of Teaching Mathematics at Elementary Level. Gomal University Journal of Research, 31(1), 20-28.

Barrish, B. (1970). Inductive Versus Deductive Teaching Strategies with High and Low Divergent Thinkers. Stanford University (Dissertation Abstract International).

Basaran, M., Ozalp, G., Kalender, İ., \& Alacaci, C. (2015). Mathematical knowledge and skills expected by higher education in engineering and the social sciences: Implications for high school mathematics curriculum. Eurasia Journal of Mathematics, Science $\mathcal{E} \quad$ Technology Education, 11(2), 405-420. https:// doi.org/10.12973/eurasia.2015.1357a

Gagani, R. F. M., \& Misa, R. O. (2017). Solo based-cognition levels of inductive reasoning in Geometry. Alberta Journal of Educational Research, 63(4), 344-356.

Gokalp, M. (2013). The effect of students learning styles on their academic success. Educational Research and Reviews, 4(10), 627-632. doi: 10.4236/ce.2013.410090

Gokkurt, B., Soylu, Y., \& Sabin, O. (2014). Analysis of the mathematical proof skills of students of science teaching. Educational Research Quarterly, 38(2), 3-22.

Hawk, T. F., \& Shah, A. J. (2007). Using learning style instruments to enhance student learning. Decision Sciences Journal of Innovative Education, 5(1), 1-19. https://doi.org/10.1111/j.1540-4609.2007.00125.x

Hussein, T., \& Fakhro, A. (2015). Guide to Thinking Skills 100 Thinking Skills (3rd Ed). Amman, Jordan: Juhayna Publishing and Distribution.

Khasawneh, A., Abu-Tineh, A., \& Obeidat, O. (2006). The relationship between learning style preferences and academic achievement of the Hashemite University students, Journal of Educational $\mathcal{E}$ Psychological Sciences, 7(3), 7-24. http://dx.doi.org/10.12785/JEPS/070311

Kolb, A. Y. (2005). The Kolb learning style inventory-version 3.12005 technical specifications. Boston, MA: Hay Resource Direct, 200(72).

Kolb, A. Y., \& Kolb, D. A. (2005). Learning styles and learning spaces: Enhancing experiential learning in higher education. Academy of management learning $\mathcal{E}$ education, 4(2), 193-212. https://doi.org/10.5465/amle.2005.17268566

Lawson, A. E. (2005). What is the role of induction and deduction in reasoning and scientific inquiry? Journal of Research in Science Teaching, 42(6), 716-740. https://doi.org/10.1002/tea.20067

Manolis, C., Burns, D. J., Assudani, R., \& Chinta, R. (2013). Assessing experiential learning styles: A methodological reconstruction and validation of the Kolb Learning Style Inventory. Learning and individual differences, 23, 44-52. https://doi.org/10.1016/j.lindif.2012.10.009

Montgomery, S. M., \& Groat, L. N. (1998). Student learning styles and their implications for teaching. Centre for Research on Learning and Teaching Occasional Papers, The University of Michigan, No. 10.

Mullis, I. V., Martin, M. O., \& Foy, P. (2005). IEA's TIMSS 2003 International Report on Achievement in the Mathematics Cognitive Domains: Findings from a Developmental Project. TIMSS \& PIRLS International Study Center, Boston College.

Obaid, W., \& Afaneh, A. (2003). Thinking and curriculum. Beirut, Lebanon Al-Falah Library for Publishing and Distribution.

Qatami, Y. (2009). Teaching Thinking for All Children (2nd ed). Amman, Jordan: Dar Al Masirah. 
Rogers, K. M. A. (2009). A preliminary investigation and analysis of student learning style preferences in further and higher education. Journal of Further and Higher Education, 33(1), 13-21. https://doi.org/10.1080/03098770802638234

Sternberg, R. J. (1994). Educational Leadership. Allowing for Thinking Styles, 52(3), 36-40.

Sudria, I. B. N., Redhana, I. W., Kirna, I., \& Aini, D. (2018). Effect of Kolb's Learning Styles under Inductive Guided-Inquiry Learning on Learning Outcomes. International Journal of Instruction, 11(1), 89-102. https:// doi.org/10.12973/iji.2018.1117a

Sims, R. R., \& Sims, S. J. (1995). The Importance of Learning Styles: Understanding the Implications for Learning, Course Design, and Education (Contributions to the Study of Education). Santa Barbara, California: Praeger Publishers Inc.

Talafah, F., \& Zoghoul, E. (2009). The preferred learning patterns of the students of Mu'tah University and its relation to sex and specialization. Damascus University Journal, 25(1).

Tulbure, C. (2011). Do different learning styles require differentiated teaching strategies? Procedia - Social and Behavioral Sciences, 11, 155-159. https://doi.org/10.1016/j.sbspro.2011.01.052

Wasserman, N. H., \& Rossi, D. (2015). Mathematics and science teachers' use of and confidence in empirical reasoning: Implications for STEM teacher preparation. School Science and Mathematics, 115(1), 22-34. https://doi.org/10.1111/ssm.12099

Merriam-Webster. (2019). Inference. Retrieve from https://www.merriamwebster.com/dictionary/inference

Wyrick, D. A. (2003). Understanding learning styles to be a more effective team leader and engineering manager. Engineering Management Journal, 15(1), 27-33. https://doi.org/10.1080/10429247.2003.11415193 